The Journal of Vitaminology 6, 308-320 (1960)

\title{
PARTICIPATION OF THIAMINE AND RIBOFLAVIN IN THE FORMATION OF TYROSINE MELANIN
}

\author{
KATSU TAKENOUCHI, KAZUO ASO AND KO UTSUMI \\ Department of Dermatology, School of Medicine, Chiba University, Chiba
}

(Received September 13, 1960)

\begin{abstract}
Melanic pigment is known to be formed in the melanocytes in the living organism with tyrosine as a substrate and tyrosinase as a catalyst. Little is known, however, about the factors which may have a controlling influence on the biosynthesis of tyrosine melanin. Radiant energy, such as ultraviolet rays, and a rise in the temperature of the skin have been claimed to activate tyrosinase, whereas sulfhydryl groups have been held responsible for inactivating the enzyme. The most plausible factors having a controlling influence on melanogenesis are considered to be the following. (a) Sulfhydryl substance inactivate the reaction by combining with the copper in tyrosinase. (b) Substances combining with the intermediate products of the reaction. (c) Substances causing a reducing process. Thiamine and riboflavin were assumed to be concerned in controlling melanogenesis, and the part played by thiamine in the biosynthesis of melanin seems to have been clarified experimentally by the authors.
\end{abstract}

EXPERIMENTAL

Methods

Histochemical identification of thiamine and riboflavin were performed according to Araki (1) as follows:

Thiamine-A piece of the tissue was soaked in $100 \%$ alcohol for 24 hours, embedded in paraffin and sections were made. After adding $40 \%$ $\mathrm{NaOH}$ and $4 \%$ potassium ferricyanide, the sections were observed with a fluorescence microscope.

Riboflavin A piece of the tissue was immersed in $100 \%$ alcohol for 24 hours, embedded in paraffin and sections were made, followed by observation with a fluorescence microscope.

Quantitative estimation of thiamine and riboflavin was performed according to Fujiwara (2) and Fujita (3) using Yagi's Fluorophotometer (500 $\mathrm{m} \mu$, filter 14-214). Dopa was estimated by Arnow's method (4). The tyrosinase used in the experiments was the product of Worthington Biochemical Corporation, Freehold, N. J., U.S.A. Tyrosine was dissolved in Clark's phosphate buffer, pH 7.0. 


\section{Results}

\section{Thiamine and Riboflavin in the Areas of Melanic Pigmentation}

Distribution of Thiamine and Riboflawin in the Skin and Hair FolliclesStudy of thiamine and riboflavin in the skin and hair follicles of a man with a fluorescence microscope revealed that these substances tended to accumulate in the basal layer of the skin and the cortex of the hair follicle which abound in melanic pigment. (Table I, Fig. 1).

TABLF I

Distribution of Thiamine and Riboflavin in the Skin and Its Appendages

(histochemical demonstration)

$\begin{array}{lcccccc}\text { Vitamin } & \text { Epidermis } & \begin{array}{l}\text { Basal } \\ \text { layer }\end{array} & \text { Papilla } & \begin{array}{l}\text { Hair } \\ \text { follicle }\end{array} & \begin{array}{l}\text { Sebaceous } \\ \text { gland }\end{array} & \begin{array}{l}\text { Sweat } \\ \text { gland }\end{array} \\ \text { Thiamine } & +4 & +4 & -4 & +4 & + & +H \\ \text { Riboflavin } & & + & & + & \end{array}$
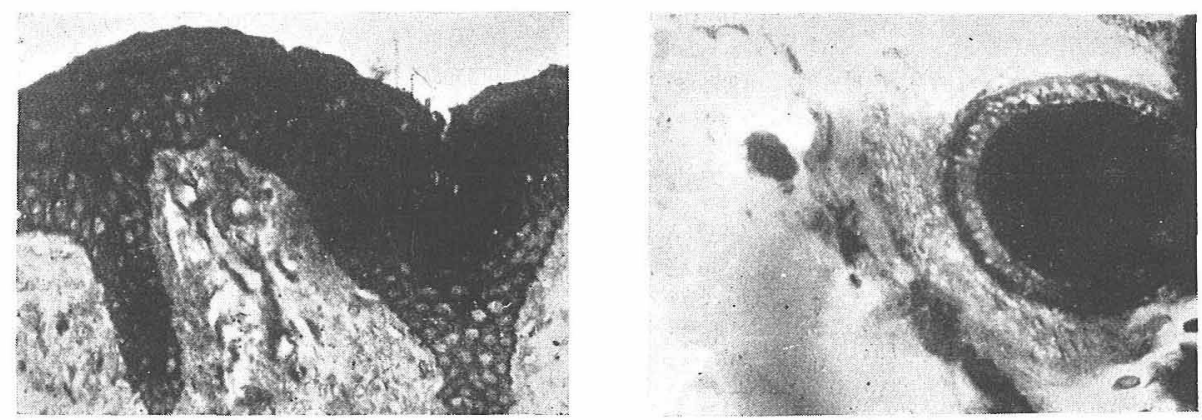

FIG. 1 Eluorescence Microscopic Demonstration of Thiamine in the Epidermis and Hair Follicle of a Man (Melanin is detected in the basal layer in the epidermis and in the cortex of the hair follicle

Thiamine and Riboflavin Levels in Gray Hair, Black Hair and the Skin of Pigmented Moles — Results of quantitative determination of thiamine and riboflavin in the hair of a guinea pig and a rabbit and the skin of pigmented moles of a man were in agreement with the findings made with a fluorescence microscope. The thiamine level in the human black hair was $0.8 \mu \mathrm{g} / \mathrm{g}$, and that in the gray hair of the same man was $0.05 \mu \mathrm{g} / \mathrm{g}$. It suggests that the black hairs contain more thiamine than the gray ones. This was also the case with the animals tested. There were great differences in thiamine level between the black and white hair of guinea pigs and rabbits (Fig. 2). Similar results were obtained in the experiments with human skin of pigmented moles. Thiamine level in the skin of pigmented moles was $0.9 \mu \mathrm{g} / \mathrm{g}$, while that in the normal skin $0.5 \mu \mathrm{g} / \mathrm{g}$. Riboflavin was also found in large amounts in the skin of pigmented moles; riboflavin level in the skin of pigmented moles was $1.32 \mu \mathrm{g} / \mathrm{g}$, while that in the normal skin adjacent to the pigmented 


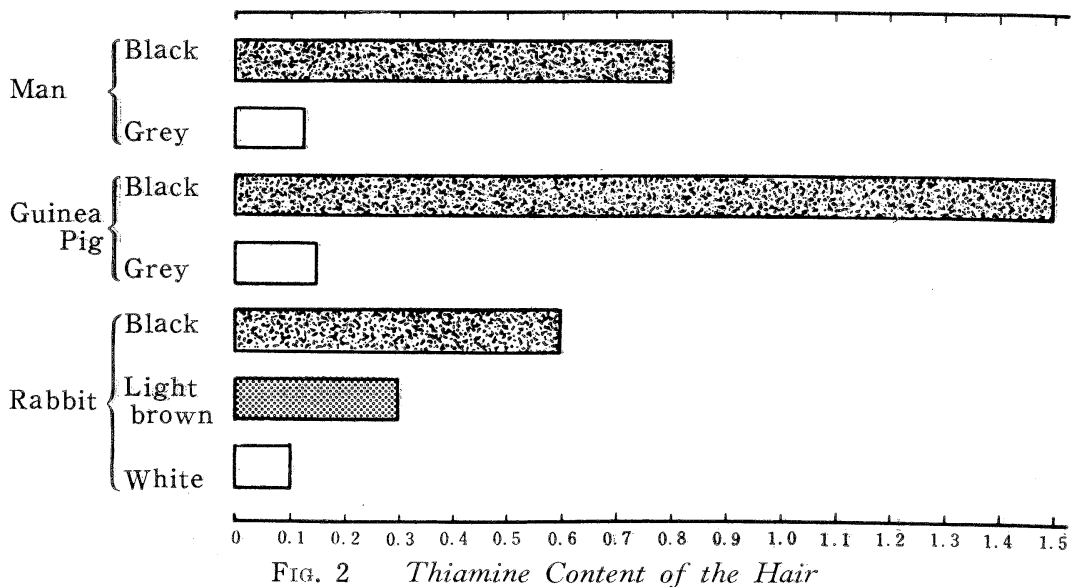

areas was $0.5 \mu \mathrm{g} / \mathrm{g}$, the former being about twice as much as the latter (Table II). Determination of the riboflavin content of various parts of the body

TABLE II

Amounts of Riboflavin in Normal Skin and Areas of Pigmentation

\begin{tabular}{|c|c|c|c|}
\hline & Epidermis & Corium & Total \\
\hline & $\mu g / g$ & $\mu g / g$ & $\mu g / g$ \\
\hline Human $\left\{\begin{array}{l}\text { Moles } \\
\text { Adjacent area }\end{array}\right.$ & $\begin{array}{l}1.62 \\
0.61\end{array}$ & $\begin{array}{l}0.69 \\
0.54\end{array}$ & $\begin{array}{l}1.32 \\
0.58\end{array}$ \\
\hline 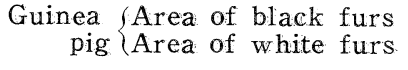 & \multicolumn{2}{|c|}{$\begin{array}{l}1.61 \\
0.56\end{array}$} & $\begin{array}{l}1.61 \\
0.56\end{array}$ \\
\hline
\end{tabular}

showed that the skin of the scrotum and axilla, the areas where much melanic pigment is present, contained more riboflavin than the skin of the abdomen and limbs which was poor in melanic pigment (Table III).

TABLE III

Amounts of Riboflavin in the Skin of Various Parts of the Body.

\begin{tabular}{lccc}
\hline Areas of the skin & Maximum & Minmum & Average \\
\hline & $\mu g / g$ & $\mu g / g$ & $\mu g / g$ \\
Abdomen & 0.79 & 0.42 & 0.58 \\
Extremity & 0.79 & 0.46 & 0.62 \\
Scrotum & 1.62 & 1.06 & 1.39 \\
Prepuce & 1.69 & 1.23 & 1.15 \\
Axillae & & & 1.47 \\
\hline
\end{tabular}

Forms of Thiamine and Riboflavin Detected in Large Amounts in the Hair and Pigmented Moles - It is noteworthy that more than 90 per cent of the thiamine detected in the black hair and pigmented moles is in the free form, and that more than 90 per cent of the riboflavin is flavin mononucleotide. 


\section{The Effect of Thiamine on Tyrosine-Tyrosinase Reaction}

The classical work of Raper (5) and of Mason (6) on the formation of tyrosine melanin is well known. Essentially, melanogenesis is the change of the colorless compound, tyrosine, to the insoluble melanic pigment. Hydroxylation to dihydroxyphenylalanine (dopa) is followed by dehydrogenation to the corresponding quinone, dopaquinone. The latter is unstable and rearranges to form an insoluble compound, leucodopachrome. It is then dehydrogenated to dopachrome, followed by decarboxylation and rearrangement to give 5,6-dihydroxyindole. This compound is assumed in some way to be converted into melanin (Fig. 3).

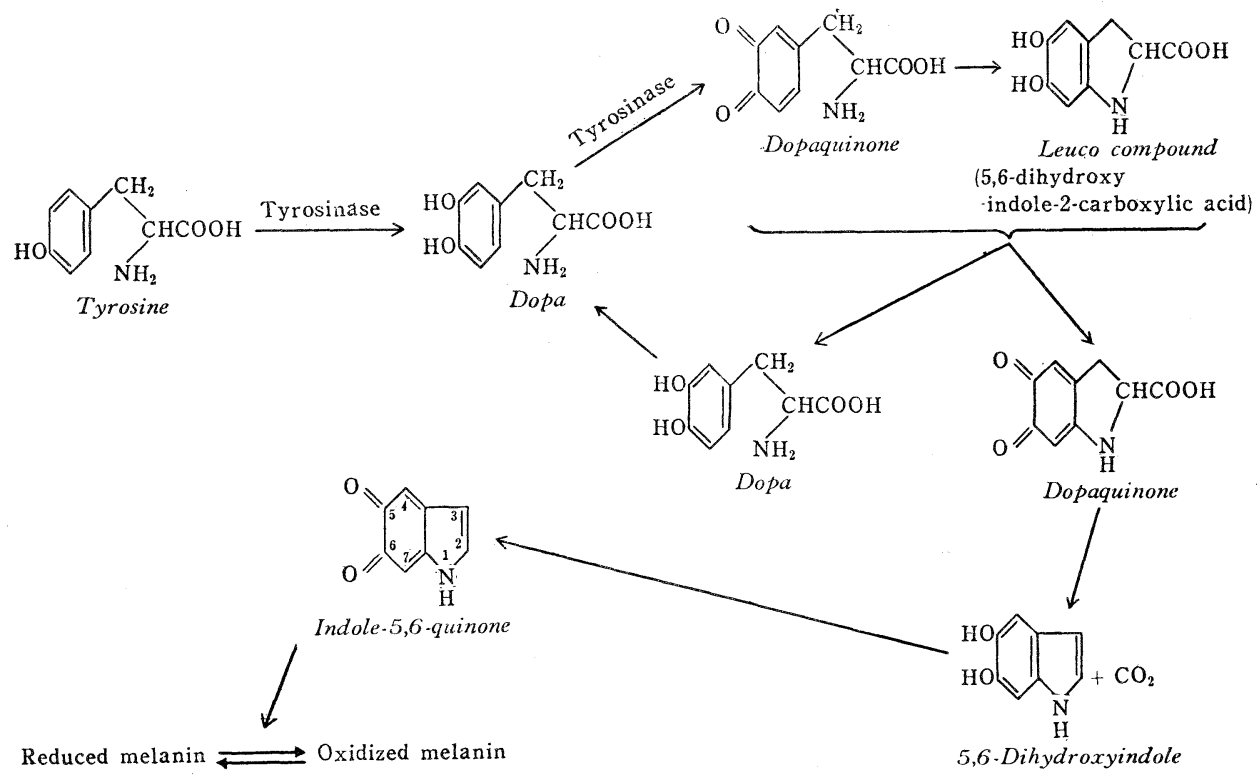

FIG. 3 Scheme of Melanin Formation according to Raper

Dopachrome, an intermediate product of tyrosine-tyrosinase reaction, develops a red color, and may be used as an index of the progress of this reaction. We observed the effect of thiamine on this reaction with Coleman's spectrophotometer, by adding thiamine to the test solution. The test solution consisted of $2 \mathrm{mg} / \mathrm{ml}$ tyrosine dissolved in Clark's buffer, $\mathrm{pH} 7.0$, and 0.05 $\mathrm{mg} / \mathrm{ml}$ of tyrosinase.

The Effect of Thiamine on the Production of Dopachrome - After adding tyrosinase, the tyrosine solution turned red in a few minutes (production of dopa). The color increased in intensity with time, becoming dark red to black and black-colored precipitates (melanic pigment) were produced in 24 hours (Fig. 4).

(a) The effect of thiamine on the production of dopachrome was studied by adding $5 \mathrm{mg}$ of thiamine to the tyrosine solution. Though the red color developed in about two minutes in the absence of thiamine, it was not until 


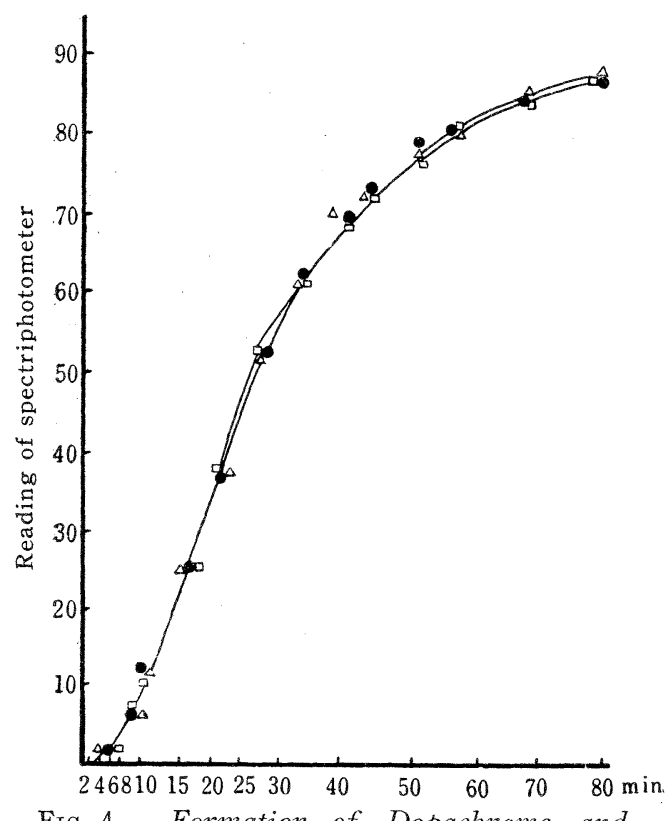

FIG. 4 Formation of Dopachrome and Melanin

Tyrosine, $2 \mathrm{mg} / \mathrm{ml}$ of $N / 15$ Clark's buffer, pH 7.0

- Control; $\triangle, 5 \mathrm{mg}$ pyridoxine;

$\square, \quad 5 \mathrm{mg}$ pantothenic acid

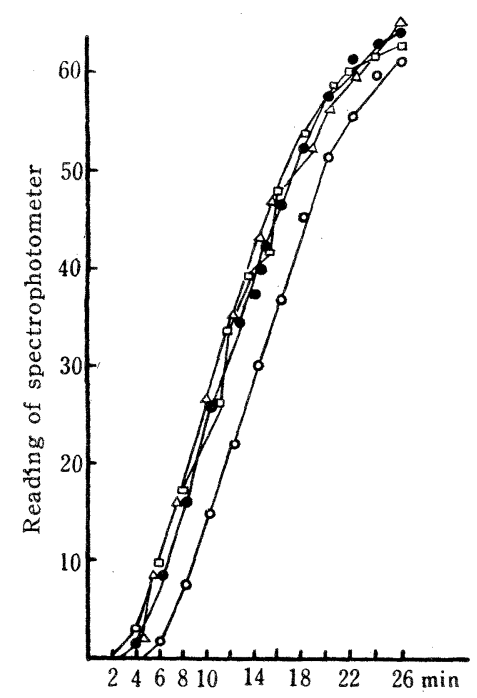

Fra. 6 Extention of the Lag Period by Varying Amounts of Thiamine

- control; $\Delta, 10 \mu \mathrm{g}$ thiamine; $\square, 50$ $\mu \mathrm{g}$ thiamine; $\mathrm{O}, 100 \mu \mathrm{g}$ thiamine

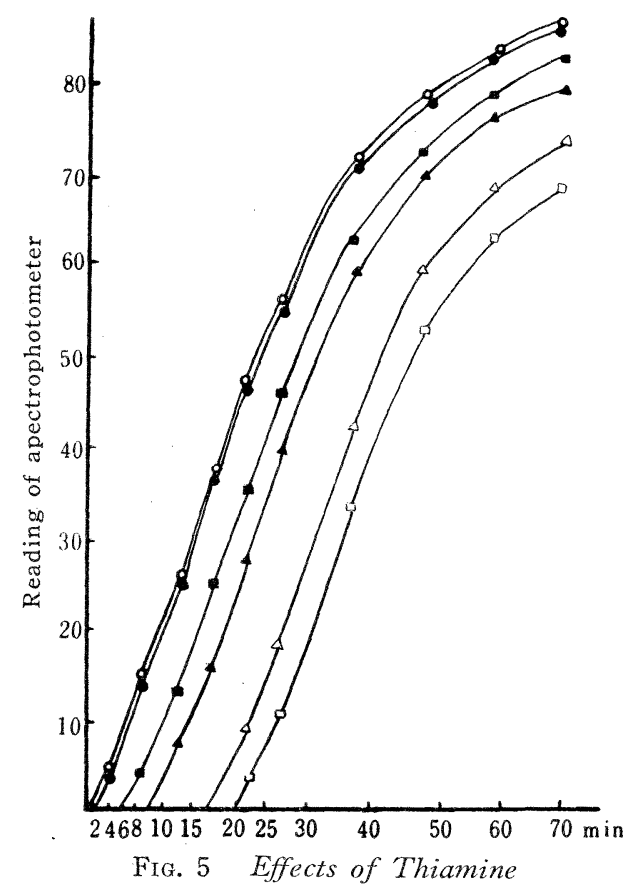

TDP, TPD and TOED on the formation of Dopachrome and Melanin

- Control; O, $5 \mathrm{mg}$ TPD ; $5 \mathrm{mg}$ TOED ;

- $1.6 \mathrm{mg}$ TDP ; $\Delta, 2.5 \mathrm{mg}$ TDP $\triangle \triangle, 5.0$ $\mathrm{mg}$ TDP; $\square, 5.0 \mathrm{mg}$ thiamine

about 20 minutes after the addition of thiamine that the solution turned red, showing the extension of the lag period. Successive reduction of the amount of the thiamine added, from 5 to $4,1.25,0.1,0.05$ and $0.01 \mathrm{mg}$, caused the extended lag period to shorten gradually until, with the addition of $0.05 \mathrm{mg}$, the spectrophotometer did not show any difference between the solution added with thiamine and that without the vitamin (Figs. 5 and 6).

(b) The addition of thiamine diphosphate (TDP) resulted in the extension of the lag period for the production of dopachrome similarly to the addition of thiamine(Figs. 5 and 7). The minimum amount of TDP required to produce this effect was $0.05 \mathrm{mg}$ 
(Fig. 7). As thiamine was present in the solution of the TDP used by the authors in Clark's buffer solution, $\mathrm{pH}$ 7.0 , in the range of 0.005 to $0.01 \mathrm{mg}$ in $5 \mathrm{mg}$ of TDP, it is clear that TDP, just like thiamine, is concerned in the extension of the lag period.

(c) It is worthy of note that the addition of neither thiamine propyl disulfide (TPD) nor thiamine- $\beta$-hydroxyethyl disulfide (TOED) caused the lag period to extend. It may be said that, unlike thiamine and TDP, the thiamine derivatives having a structure of disulfide, such as TPD and TOED, are not concerned in extending the lag period.

(d) The addition of $5 \mathrm{mg}$ of cysteine or of ascorbic acid inhibited the production of dopachrome.

The Effect of Thiamine on Oxygen Consumption - Melanogenesis is the enzymatic oxidation of tyrosine. Each of tyrosine and dopa is known to re-

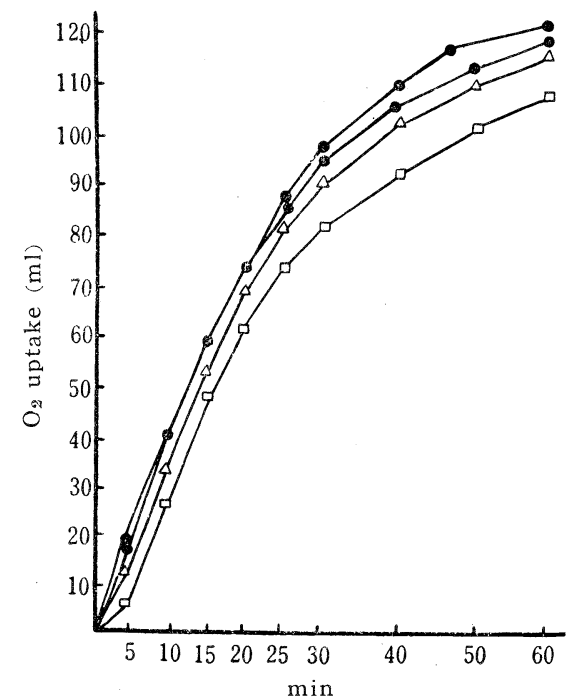

FIg. 8 Decrease of Oxygen Consumption by Adding Varying Amounts of Thiamine - control; $\triangle, 3 \mathrm{mg}$ thiamine; $\square, 5 \mathrm{mg}$ thiamine.

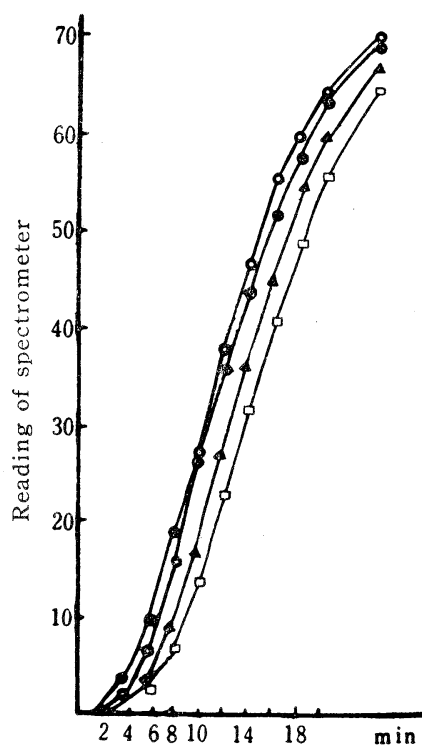

FIG. 7 Extension of the Lag Period by Varying Amounts of Thiamine Diphosphate

-, control; $0,10 \mu \mathrm{g}$ TDP ; $\Delta, 50 \mu \mathrm{g}$ TDP ; $\square, \quad 100 \mu \mathrm{g}$ TDP

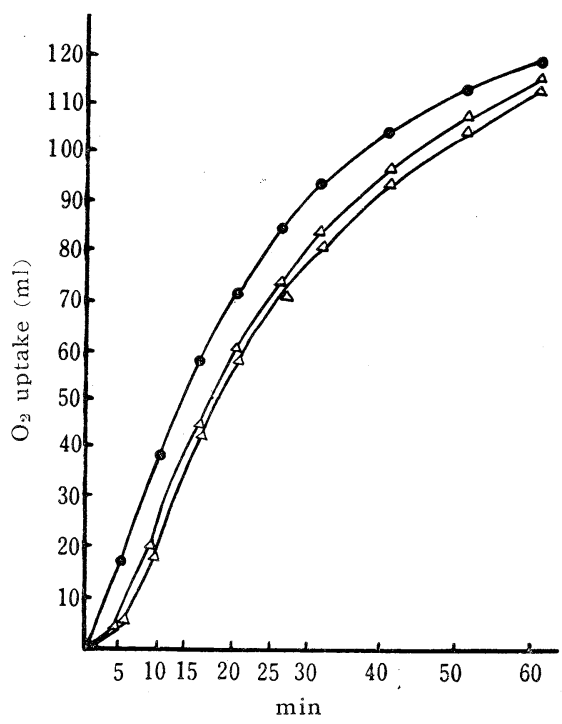

Fig. 9 Decrease of Oxygen Consumption due to the Addition of Thiamine Diphosphate

- control; $\triangle, 5 \mathrm{mg}$ TDP 
quire 4 or 5 oxygen atoms for oxidation. Using Warburg's monometer, the effect of thiamine on the oxgen consumption of the reaction was studied. The conditions of the experiments were as follows. $2 \mathrm{mg} / \mathrm{ml}$ tyrosine in N/15 Clark's phosphate buffer, $\mathrm{pH} 7.0$, was added to the thiamine solution in the main chamber; $0.05 \mathrm{mg} / \mathrm{ml}$ tyrosinase in the side bulb; $20 \% \mathrm{KOH}$ in the center well; $\mathrm{O}_{2}$ as a gas phase; the temperature was kept at $37.5^{\circ}$.

(a) Oxygen consumption of the test solution without thiamine (the control) was $120 \mu 1$ per hour (Fig. 8).

(b) The test solution added with $3 \mathrm{mg}$ of thiamine showed a markedly reduced oxygen consumption. When thiamine added was increased in amount to $5 \mathrm{mg}$, oxygen consumption showed a further reduction (115-105 $\mu 1)$.

(c) The addition of TDP also caused the oxygen consumption of the test solution to decrease $(110 \mu 1)$ (Fig. 9).

The Effect of Thiamine on the Production of Dopa-Dopa, the first intermediate product of the enzymatic oxidation of tyrosine, is in itself a catalyst of tyrosine oxidation. The authors thought that quantitative determination of the dopa produced in the reaction might give an idea of the way in which thiamine interfered the reaction. For that purpose, $0.5 \mathrm{ml}$ of $0.05 \mathrm{mg} / \mathrm{ml}$ tyrosinase and $0.25 \mathrm{mg}$ of tyrosine solution were mixed and the dopa produced was determined. For testing the effect of thiamine, $0.5 \mathrm{mg} / \mathrm{ml}$ of standard thiamine solution was added to the mixture.

(a) Control experiment: The amount of dopa produced 10 minutes after the reaction started was $4.5 \mu \mathrm{g}$, rising gradually thereafter, and reached the level of $90 \mu \mathrm{g}$ in 60 minutes (Table IV, and Fig. 10).

(b) Experiments with addition of thiamine: When $0.25 \mathrm{mg}$ of thiamine

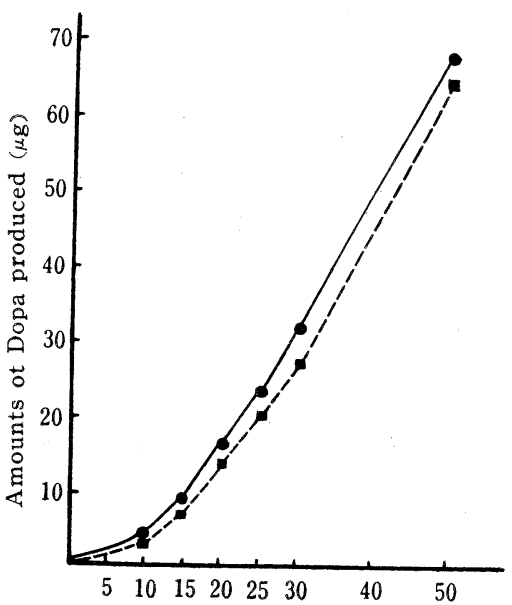

Time elapsed after the addition of tyrosinase (min)

Fig. 10 Effects of Thiamine on the Amount of Dopa Produced in TyrosineTyrosinase Reaction

- control; $\mathbf{\square}$, thiamine added was added to the test solution, the

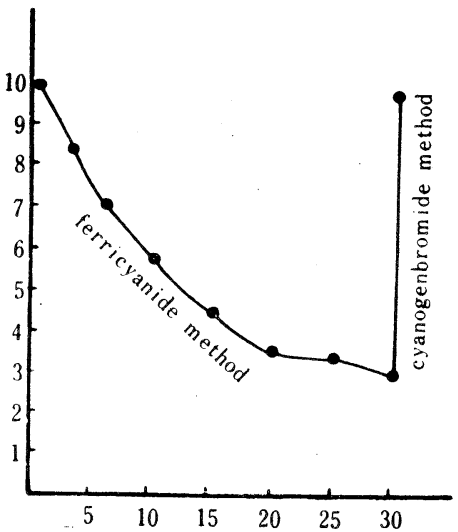

FIG. 11 Quantitative Detımination of Thiamine Added to Tyrosine-Tyrosinase Reaction. Comparison of Ferricyanide and Cyanogen Bromide Method

Tyrosine : $2 \mathrm{mg} / \mathrm{ml} / \mathrm{N} / 15$ Clarks' buffer $\mathrm{pH}$ 7.0 ; tyrosinase : $0.5 \mathrm{ml}$ of $0.05 \mathrm{mg} / \mathrm{ml}$ Yagi's fluorophotometer used. 
amount of dopa produced in 10 minutes was $3.5 \mu \mathrm{g}$. It increased gradually, reaching the level of $86.5 \mu \mathrm{g}$ in 60 minutes (Table IV, and Fig. 10). The data given in Table IV led us to conclude that the addition of thiamine diminished the amount of dopa produced in the reaction.

TABLE IV

Effect of the Addition of Thiamine on the Amounts of the Dopa

Produced in Tyrosine-Tyrosinase Reaction

\begin{tabular}{ccc}
\hline \hline \multirow{2}{*}{$\begin{array}{c}\text { Time after addition } \\
\text { of tyrosinase }\end{array}$} & \multicolumn{2}{c}{ Amounts of dopa produced } \\
\cline { 2 - 3 } min & Without thiamine & $250 \mu \mathrm{g}$ of thiamine added \\
0 & $\mu g$ & $\mu g$ \\
5 & 0 & 0 \\
10 & $?$ & $?$ \\
15 & 4.5 & 6.5 \\
20 & 9.5 & 13.5 \\
25 & 16.5 & 20.0 \\
30 & 22.5 & 26.5 \\
50 & 31.5 & 64.0 \\
60 & 68.0 & 86.5 \\
\hline
\end{tabular}

Our experiments have shown that thiamine accumulates in large amounts in the areas of melanic pigmentation in the skin. It has also been shown by in vitro experiments that the thiamine added to a tyrosine-tyrosinase reaction system inhibits the production of melanin. On the other hand, the fact that the areas of melanic pigmentation in the skin are rich in thiamine and riboflavin would suggest the role of these substances as an accelerator of melanin formation, similarly to the presence of large amounts of copper in the same areas, as claimed by Gordon (7), would indicate active melanin formation. However, the experimental results showing the inhibition of melanin formation by thiamine do not support the above assumption.

3. The Behavior of Thiamine Added to Tyrosine-Tyrosinase Reaction System

Quantitative determination of thiamine depends on the estimation of thiochrome. There are two methods for oxidation of thiamine, one is a ferricyanide method and the other is cyanogen bromide method. When the former method is employed, the reaction may be influenced by a reducing agent occurring in the test solution. However, if the latter method is used, this is hardly the case.

Quantitative Determination of Thiamine after Adding Tyrosinase to the Mixture of Tyrosine and Thiamine

(a) Following the addition of $0.5 \mathrm{ml}$ of $0.05 \mathrm{mg} / \mathrm{ml}$ tyrosinase solution to

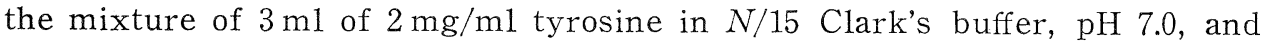
$10 \mu \mathrm{g}$ of thiamine, the vitamin was estimated at 5-minute intervals for 30 minutes. Thiamine decreased with time, the original amount of $10 \mu \mathrm{g}$ being decreased to $3 \mu \mathrm{g}$ in 30 minutes (Figs. 11 and 12).

(b) When cyanogen bromide method instead of ferricyanide method was 
employed in the oxidation of thiamine, the vitamin added was completely recovered at each time of observation.

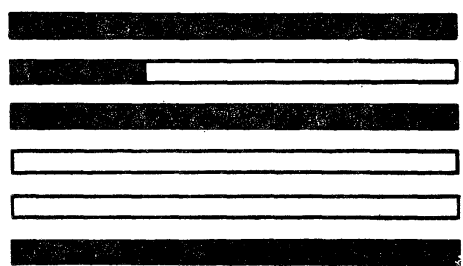

a) $\mathrm{T}+\mathrm{B}_{1}$

b) $T+B_{1}+T$-ase

c) $\mathrm{T}+\mathrm{B}_{1}+\mathrm{T}$-ase

d) $\mathrm{T}+\mathrm{TPD}+\mathrm{T}$-ase

e) $\mathrm{T}+\mathrm{TPD}+\mathrm{T}$-ase

f) $\mathrm{T}+\mathrm{TPD}+\mathrm{T}$-ase + Cys $($ Ferri $\cdot \mathrm{BrCN})$
(Ferri. BrCN)

(Ferri)

$(\mathrm{BrCN})$

(Ferri)

$(\mathrm{BrCN})$

In $a, c$ and $d$, the formation of black pigment was confirmed 24 hour after the additition of tyrosinase. Then diastase was added, TDP was converted to free thiamine, which was esti. mated either by ferricyanide method or cyanogen bromide method using Yagi's fluorophotometer.

FrG. 12 Behavior of Thiamine Diphosphate Added to Enzymatic Oxidation of Tyrosine

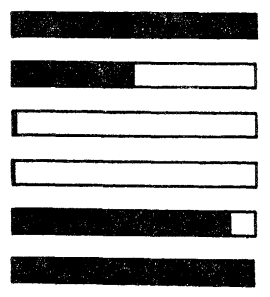
a) $\mathrm{T}+\mathrm{TDP}+\mathrm{D}($ Ferri. $\mathrm{BrCN})$
b) $\mathrm{T}+\mathrm{TDP}+\mathrm{T}$-ase $+\mathrm{D}($ Ferri)
c) $\mathrm{T}+\mathrm{TDP}+\mathrm{T}$-ase (Ferri)
d) $\mathrm{T}+\mathrm{TDP}+\mathrm{T}$-ase $(\mathrm{BrCN})$
e) $\mathrm{T}+\mathrm{TDP}+\mathrm{T}$-ase $+\mathrm{D}(\mathrm{BrCN})$
f) $\mathrm{T}+\mathrm{TDP}+\mathrm{T} \cdot \mathrm{ase}+\mathrm{D}+\mathrm{Cys}(\mathrm{BrCN})$

$\mathrm{D}=$ diastase $; \mathrm{T}=$ tyrosine $;$ Ferri $=$ ferricyanide method; Cys $=$ cysteine ; $\mathrm{T}$-ase $=$ tyrosinase

$\mathrm{BrCN}=$ cyanogen bromide method

FIG. 13 Change of TDP Added to TyrosineTyrosinase Reaction

48 hours after the reaction started.
$\mathrm{T}=$ tyrosine

$T$-nase $=$ tyrosinase

Cys $=$ cysteine

Ferri $=$ ferricyanide method

$\mathrm{BrCN}=$ cyanogen bromide method

containing: $0.01 \mu \mathrm{g}$ of free thiamine in N/15 Clark's buffer, pH 7.0, was mixed with tyrosine and the mixture was allowed to stand for 48 hours after addition of tyrosinase solution, the amounts of the vitamin detected were as follows:

$2 \mu \mathrm{g}$ of thiamine; $0.1 \mu \mathrm{g}$ of thiochrome; $10 \mu \mathrm{g}$ of thiamine was detected by ferricyanide method and $19.8 \mu \mathrm{g}$ (98 to 99 per cent of the original amount) by cyanogen bromide method after treatment with Takadiastase. When Takadias tase and $3 \mathrm{ml}$ of $100 \mathrm{ml} / \mathrm{dl}$ cysteine were added to the test solution and the mixture was allowed to stand for 24 hours, $20 \mu \mathrm{g}$ of thiamine was obtained by both methods (Fig. 13).

(e) Paper chromatographic separation. A tyrosine solution containing 5 $\mathrm{mg}$ of thiamine was allowed to stand for 24 hours after addition of tyrosinase. Then, it was chromatographed on Toyo filter paper No. 15 using a solvent system, acetic acid-butanol-water $(1: 4: 5)$, at about $20^{\circ}$ for 12 hours by an as- 


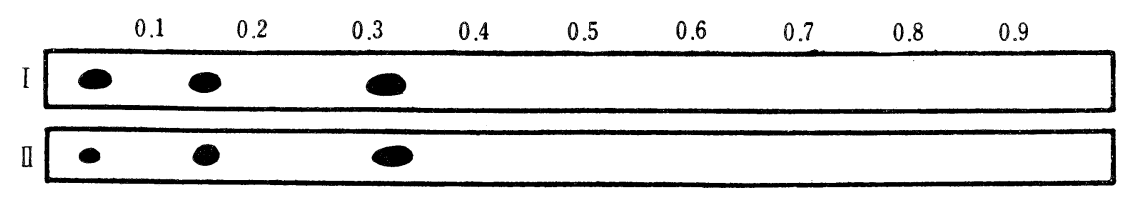

FIG. 14 Paper Chromatography of Reaction Solution

$\mathrm{I}$, tyrosine + thiamine $(500 \mu \mathrm{g})+$ tyrosinase : ferricyanide

II, tyrosine + thiamine $(500 \mu \mathrm{g})+$ tyrosinase : cyanogen bromide

cending technique. The spots corresponding to thiamine $\left(R_{\mathrm{F}} .0 .02\right)$ and thiochrome $\left(R_{\mathrm{F}}, 0.32\right)$, as well as the spot at $R_{\mathrm{F}} .0 .17$, were revealed. The latter was located by ultraviolet light after spraying with either alkaline ferricyanide or alkaline cyanogen bromide. No other spots were revealed by spraying with cysteine (Fig. 14). The behavior of the thiamine added to tyrosine-tyrosinase reaction system led us to assume that some reducing mechanism is involved in melanogenesis. This hypothesis is supported by the fact that, while only 30 per cent of the thiamine added to tyrosine-tyrosinase reaction was recovered by ferricyanide method in 30 minutes, 100 per cent of it was recovered by cyanogen bromide method. In view of the facts that thiamine of disulfide type was detected, though small in amount, after addition of cysteine, and that paper chromatography revealed the spot of thiochrome and a spot at $R_{\mathrm{F}} 0.17$, it would be natural to conclude that thiamine undergoes decomposition in tyrosinetyrosinase reaction.

\section{DISCUSSION}

The mechanism of tyrosine-tyrosinase reaction has been clarified by Raper and Mason. Raper's famous formula on the formation of tyrosine melanin has been established on the basis of the observation that the following three intermediate products were identified, using tyrosinase from meal worms, following the maximum development of red color (dopachrome) at $\mathrm{pH} 6.0$ and inactivation of tyrosinase (Fig. 3).

There is a lag period before oxidation of tyrosine by tyrosinase takes place. In our control experiment, a lag period of 1 to 2 minutes was noticed before dopachrome was produced. It is not until after this period that the reaction takes place (see Fig. 4). A small amount of dopa added to the reaction solution shortens the lag period as observed by Lerner and Fitzpatrick (8). It may be said that dopa, the first intermediate product of tyrosine oxidation, acts as a catalyst, shortening the lag period and accelerating the reaction.

Raper thought that there must be some reducing mechanism responsible for reproduction of dopa, if dopa were to act as a catalyst in this reaction. As the addition of leuko compound caused dopa to accumulate, he supposed that the reproduction of dopa would result from the following, possibly irreversible, reaction.

$$
\text { Dopaquinone }+ \text { leuco compound }=\text { dopa }+ \text { dopachrome }
$$


Raper held a view that not only the reaction between leuco compound and dopaquinone, but also the reaction between 5,6-dihydroxyindole and dopaquinone would be responsible for the production of dopa. The fact that the amount of dopa produced in the first 2 to 5 hours of tyrosine-tyrosinase reaction was 10 to 20 per cent more than the amount of dopa to be produced theoretically from tyrosine, would support the theory on the mechanism of dopa reproduction as outlined above.

Hasegawa, Sakamoto, Nagayama and Fujita (9) have shown that active principles of the thiamine-decomposing substance occurring widely in plants is flavinoids. Matsukawa and Kawakami (10) have found that phenol and quinones are capable of decomposing thiamine. Hosoda, Hasegawa and Fujita (11) have isolated the reaction product between thiamine and various phenols in a crystalline form, and have identified it as thiamine disulfide. As catechol and hydroquinone are potent reducing agents, they can not be expected to oxidize thiamine directly, but the quinones corresponding to the hydroquinones seem to decompose thiamine. Their experiments on the degradation of thiamine by benzoquinone, showed the ability to degrade thiamine 10 times as great as that of hydroquinone. They assumed the action mechanism of thiamine-decomposing thermostable factors to be as follows: diphenols are oxidized by oxygen to quinones, which in turn oxidize thiamine to thiamine disulfide.

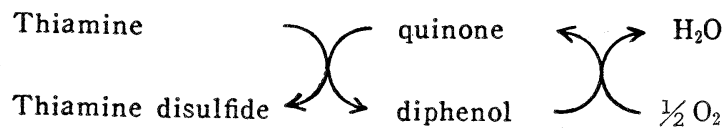

The above mode of thiamine decomposition by quinone provides a clue to understand the results of our experiments that the thiamine added to a tyrosine-tyrosinase system extended the lag period, retarding the production of dopachrome. Dopa, as pointed out by Raper, is a catalyst indispensable to tyrosine-tyrosinase reaction.

When thiamine is added to this reaction system, it replaces leuco compound, reacting with dopaquinone, thus reducing the amount of dopa to be reproduced, as well as the production of dopachrome. As a result, the lag period is extended. Our experiments have proved that thiamine is oxidized by dopaquinone.

In the light of the knowledge thus obtained, the reason why large amounts of thiamine is found in the areas of melanic pigmentation would be as follows:

Activation of tyrosinase in the skin and hair results in the production of dopa and dopaquinone. On the other hand, dopaquinone reacts with leuco compound to reproduce dopa. Thiamine found in the skin in large amount $(0.5 \mu \mathrm{g} / \mathrm{g})$ reacts with dopaquinone (and with dopa, of course), and inhibits the production and reproduction of dopa, retarding the reaction. Thiamine, after thus interfering in the reaction, is converted by dopa or dopaquinone into thiamine disulfide or other decomposition products.

These decomposition product of thiamine have nothing to do with the 
formation of melanic pigment. They accumulate in large quantities in the hair in which melanogenesis goes on for a long period of time. It is impossible to eliminate cysteine in the hair in quantitative determination of thiamine in the hair. So, it might be that thiamine disulfide in the pigmented hair and skin is converted into thiamine by the cysteine in the hair and is estimated as thiamine.

There is a work of Robert and his colleagues (12) on the relation of thiamine to the formation of tyrosine melanin. Assaying histaminase in the skin, they found that the skin of leukoderma vulgaris was deficient in histaminase, and that the skin of pigmented moles was rich in the enzyme. From this observation he assumed that histamine might be the substrate of melanin. Furthermore, Robert and Zürker (12) have demonstrated in in vitro experiments that thiamine inhibits the auto-oxidation of dopa. This theory was confirmed by Schuppli. So they concluded that thiamine might inactivate histaminase, an oxidizing enzyme of histamine, which is, according to them, the substrate of melanin. They claimed the validity of their theory on the basis of their observation that the thiamine contained in the skin of leukoderma vulgaris was 75 per cent more than that contained in the normal skin adjoining the leukodermic patches, and that administration of thiamine caused the vitamin in the skin of leukodermic patches to increase still further. Apart from the problem whether histamine is the substrate of melanin, there may have been some mistake in their experiments to make a report that thiamine contained in the skin of leukodermic patches was larger in amount than the vitamin contained in the normal skin. Their method of determining thiamine in the skin consisted in the estimation of the thiamine "dialyzed" into the glass ware containing distilled water which was kept fastened to the skin for 10 hours. It is doubtful, whether the thiamine in the skin can be estimated correctly by such a method. Thiamine thus collected would be the thiamine flowed out of the sweat glands (normal thiamine level in the sweat is $0.05 \mu \mathrm{g} / 100 \mathrm{ml}$, and the level increases if thiamine is administered). Our experiments with 6 cases of leukoderma vulgaris showed that the thiamine level in the skin of leukodermic patches was $0.53 \mu \mathrm{g} / \mathrm{g}$, while that in the normal skin adjacent to the leukodermic patches was $0.47 \mu \mathrm{g} / \mathrm{g}$, there being no difference of significance. Experiments with 4 guinea pigs on the thiamine level in the skin of pigmented hair and the skin of nonpigmented hair of the same animal also revealed no significant difference. That there was no difference in the amount of thiamine between the leukodermic skin and the normal skin as well as the skin of pigmented hair and that of non-pigmented hair of a guinea pig is accounted for by the fact that a difference in the degree of melanic pigmentation between these two kinds of skin is not so great as a difference between the black and gray hair. There was a marked difference in the level of thiamine between the skin of pigmented mole $(0.9 \mu \mathrm{g} / \mathrm{g})$ and the normal skin adjoining them $(0.5 \mu \mathrm{g} / \mathrm{g})$. We cannot, therefore, accept the theory of Robert and his colleagues that thiamine is detected in large amounts in the skin of leukodermic patches. 


\section{SUMMARY}

The areas of melanic pigmentation were found to contain much thiamine and riboflavin. Thiamine and riboflavin detected in these areas are mostly in the free form and flavinmononucleotide. The role of thiamine played in melanogenesis was further investigated. Thiamine, added to tyrosine-tyrosinase reaction is assumed to act as follows: it interferes in the action of dopa or dopaquinone, inhibits the production of dopa, extends the lag period of this reaction, and is in itself oxidized to thiamine disulfide.

The inhibitory action of thiamine in melanogenesis would not be so strong as that of reducing agents, such as ascorbic acid or cysteine; it would be just enough to adjust the progress of melanogenesis in such a way that it may not proceed too fast.

\section{REFERENCES}

1. Araki, M., Chin, S., J. Vitaminol. 2, 128 (1956).

2. Fujiwara, M., Quantitative Determination of Vitamins (Japanese), p. 1, Medical and Dental Publications (1954).

3. Fujita, A., Vitamins 2. 254, (1950).

4. Arnow, E., J. Biol. Chem. 118, 531 (1938).

5. Raper, H.S., and Lorinz, A.L., Biochem. J. 17, 455, (1923); Physiology and Biochemistry of the Skin by Rothman, S. P. 516, The University of Chicago Press (1954).

6. Mason, H.S., Pigment Cell Growth by Gordon, M. P. 277, Academic Press, New York, (1953).

7. Gordon, M., ibid. P. 43.

8. Lerner, A. B., and Fitzpatrick, T.B., Physiol. Rev. 30, 98 (1950).

9. Hasegawa, E., Sakamoto, S., Nagayama K., and Fujita, A., J. Vitaminol. 2, 31 (1956).

10. Matsukawa, D., and Kawakami, T., ibid. 1, 208 (1955).

11. Hosoda, S., Hasegawa, E., and Fujita, A., ibid. 4, 251 (1958).

12. Robert, A., Zürcker, H., and Müller, R., Dermatologica 102, 4/6 (1951). 